\title{
Parametric Analysis of the Effect of Engine Speed and Load on the Hydrodynamic Performance of the Lubricant in Diesel Engine
}

\author{
Brahim Menacer ${ }^{1,2 *}$, Mostefa Bouchetara ${ }^{2}$ \\ ${ }^{1}$ Higher School of Electrical and Energetic Engineering Oran (ESGEE), 31000 Oran, P. O. B. 64 CH2, Algeria \\ ${ }^{2}$ Laboratory of Gas Combustion and Environment, Department of Mechanical Engineering, University of Sciences and the \\ Technology of Oran, 31000 Oran, El-Menaouer, P. O. B. 1505, Algeria \\ * Corresponding author, e-mail: menacer_brahim@esgee-oran.dz
}

Received: 10 February 2020, Accepted: 12 August 2020, Published online: 17 September 2020

\begin{abstract}
The oil consumption in an internal combustion engine is an important source of pollution and particulate emissions, main efforts are done by the manufacturers to reduce to the maximum the impact of the oil consumption on the emissions of the engine, and to satisfy the increasingly rigorous standards of pollution. The losses by friction due to piston ring friction explain $20 \%$ of the total mechanical losses in internal combustion engines. A reduction in piston ring friction would therefore result in higher efficiency, lower fuel consumption and reduced emissions. The goal of this study is to develop a numerical method by using of GT-Suite software to analyze the influence of engine speed and engine load during the working cycle on oil film thickness, frictional force, power losses. Our predicted results were validated with the experimental data of a previous study, and they have shown a good agreement. The results in the current analysis demonstrated that the engine speed and load have a remarkable effect on oil film thickness, friction force and friction power losses between the top ring and cylinder liner. So, it would help in reducing friction as well as making a contribution towards the improvement of engine performance such as torque, efficiency and fuel consumption.
\end{abstract}

\section{Keywords}

hydrodynamic lubrication, power losses, oil film thickness, piston ring, cylinder liner, diesel engine, gas dynamics

\section{Introduction}

The segments oil flow through the combustion chamber explains 40 to $80 \%$ of the total oil consumption in the engine [1]. Minimizing oil consumption due to segmentation is therefore of primary interest which can significantly reduce emissions. On the other hand, the segments-liner contact friction is a function of the geometric agreement of the triplet and therefore inversely related to the oil consumption, which explains 10 to $20 \%$ of the power losses by friction in the engine. For that, designing a piston and segments of recognized efficiency and reliability remains today a most demanding challenge for manufacturers and equipment manufacturers in the automotive sector. Several researchers have attempted to understand the mechanism of movement of piston rings by numerical and experimental investigations. Harigaya et al. [1] presented the oil film thickness variation of the upper and secondary segments of a truck diesel engine during a cycle by means of capacitive sensors for clearance in the sliding surfaces of the segments.
Radakovic and Khonsari [2] analyzed the governing equations and the appropriate numerical resolution method to process thermohydrodynamic problems involving thin film flows in the presence of transverse compression and shear thinning and the thermal and shear effects of the oil film on the performance of the rings. For the study of tribological characteristics, Chaudhari and Sutaria [3] made a comparison between the obtained results by numerical modeling of the friction force of the different friction sources and the experimental results. Guo et al. [4] used Pro/Engineer software to design three piston rings with different profiles for a diesel engine and studied the stresses and displacements of the piston and piston rings. The focus of this study is to investigate the main friction characteristics (such as minimum film thickness, friction force, and frictional power loss) between the top piston ring and the cylinder liner by taking into account changes in engine speed and engine load in order to maximize the torque and power of diesel engine. Therefore, 
this study quantified the correlation between engine friction measurement and calculation. The estimated results for the developed friction models were validated using the reference measurement data. In the calculation process for modeling, the lubricant oil film pressure and thickness were calculated to determine the friction force and the power loss of each crank angle.

\section{Modeling assumptions of piston-ring-liner}

The pressure in the combustion chamber is considered as one of the inputs for the simulated engine code was modulated using the first law of thermodynamics [5]. For the simulation model, we take into account the following hypotheses [6]:

- The shear friction of the lubricant given by the Reynolds equation and friction due to the GreenwoodTripp roughness contact are considered the main friction between the rings and the liner.

- The hydrodynamic pressure distribution between running surface of the ring and the liner is determined by solving the Reynolds equation in each time step [7].

- The volumes are connected due to the actual clearances of ring end gaps and the actual position of the rings in the grooves. The gas flow behind the rings and between ring and groove flanks is considered [8].

- The oil film is taken into account between the ring running surface and liner by calculating the pressure distribution in the clearance.

- It was assumed that the ring contracts and extends uniformly around the circumference and that the ring sits on a single point with a running contact on the top or bottom of the groove. The contact points also seal the pressure on one side from the other, so that there is a gradual change in pressure at this contact point.

- The lubrication regime in the cylinder is influenced by the variation in piston speed, which affects the friction between the piston ring and the liner throughout the piston stroke. In this study, we consider hydrodynamic lubrication, which means that the ring always moves over a complete fluid film.

- The frictional force reaches its maximum where the piston speed is highest, i.e. the piston position is at mid-stroke. If the engine speed or oil viscosity is high, a thick oil film is formed which is not completely ejected even at dead centers where the piston speed is zero $[9,10]$.

\section{Governing equations for piston ring friction and lubrication}

\subsection{Kinematic relationships of connecting rod and crank mechanism}

The position of the piston will not be affected by the piston ring action due to the high inertia of the connecting rod crank system. The piston axial position $x$, speed $U$ and acceleration a relative to the liner as a function of crankshaft angular position, measured from TDC, are given respectively by [11]:

$$
\begin{aligned}
& x=R \cos \theta+R \sqrt{1-\left(\frac{R}{L}\right)^{2} \sin ^{2} \theta}, \\
& U=\frac{d x}{d t}=R \omega\left[\sin \theta+\frac{R}{2 L} \sin 2 \theta\left(1-\left(\frac{R}{L}\right)^{2} \sin ^{2} \theta\right)\right], \\
& a=\frac{d^{2} x}{d t^{2}}=R \omega^{2}\left[\cos \theta+\frac{R}{L} \frac{\cos 2 \theta+\frac{R}{L} \sin ^{4} \theta}{\left(1-\left(\frac{R}{L}\right)^{2} \sin ^{2} \theta\right)^{3 / 2}}\right] .
\end{aligned}
$$

In Eqs. (1) to (3):

- $R$ : crank radius $[m]$,

- $L$ : distance between bearing centers on the connecting-rod and the crankshaft lies in the same plane as the piston motion [m],

- $\omega$ : crankshaft angular velocity $[1 / \mathrm{s}]$

- and $t$ : time [s].

\subsection{Reynolds equation}

In the case of hydrodynamic lubrication, the oil fully supports the load of the ring on the liner, and therefore the frictional force generated by the segment-liner interaction depends on the lubricant properties, the height and width of the film below the ring surface. To determine the frictional force, coupled equations governing the fluid mechanics of the lubricant and the forces acting on the segment have to be solved. Fig. 1 shows the schematic of studied system. In the general case, the unknowns are the minimum oil film thickness $c$, the input wetting coordinate $x_{1}$ and the output wetting coordinate $x_{2}$. Between both coordinates, there is a transition area where the oil attaches and detaches from the ring. Although this zone has a very small axial width compared to the axial width of the ring, it has an important function in the lubrication of the system.

In the Reynolds equation:

- $w$ : the net resultant radial force [N],

- $a$ the width of parabolic portion of the ring face [mm], 


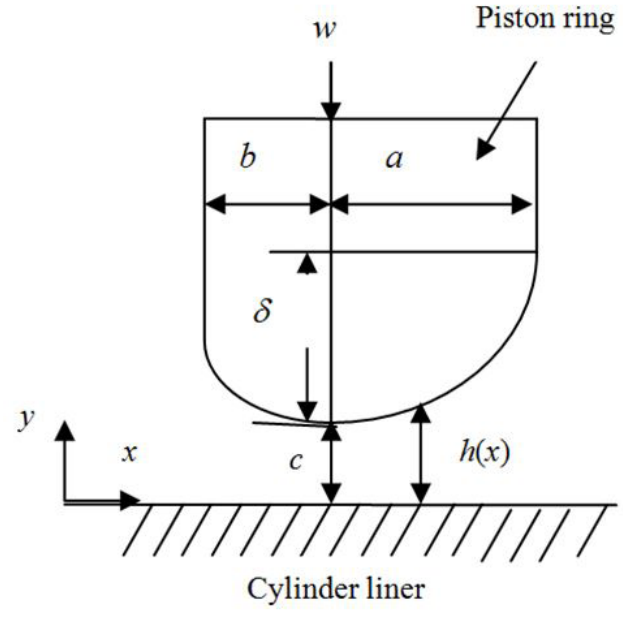

Fig. 1 Hydrodynamic lubrication between the ring and the liner.

- $b$ the width of the straight portion of the ring face $[\mathrm{mm}]$;

- $\delta$ the inclination of the wedge $\left[{ }^{\circ}\right]$

- and $c$ minimum film thickness [mm].

Reynolds' equation gives the relationship between the height, width and the oil film thickness between ring and liner and the oil pressure gradient. We used a 2-D approach in which the ring and liner lubrication parameters are determined as a function of piston position, and the Reynolds equation is thus reduced to a 1-D form. Based on these conditions, the Reynolds equation becomes [12-14]:

$\frac{\partial}{\partial x}\left(h^{3} \frac{\partial P}{\partial x}\right)+\frac{\partial}{\partial y}\left(h^{3} \frac{\partial P}{\partial y}\right)=6 a \eta \frac{\partial h}{\partial x}+6 v \eta \frac{\partial h}{\partial y}+12 \eta \frac{d h}{d t}$,

where $h$ is the oil film thickness under the ring as function of the coordinate distance calculated from the leading edge of the ring $x[\mathrm{~mm}], U$ the piston velocity and $\eta$ lubricant viscosity [cst].

Taking into account the symmetry of the axes along the cylinder axis, Eq. (4) becomes [15]:

$\frac{\partial}{\partial x}\left(h^{3} \frac{\partial P}{\partial x}\right)=6 U \eta \frac{\partial h}{\partial x}+12 \eta \frac{d h}{d t}$.

The film thickness variation under the ring with respect to position and time is [16]:

$h(x, t)=h_{p}(x)+h_{r}(t)+a(t) \times x$,

where $h_{p}$ is the ring profile height $[\mathrm{m}]$ and $h_{r}$ is the ring reference distance $[\mathrm{m}]$.

The surface shear stress of lubricant between two parallel plates is given by the following relationship:

$\tau(x)=\frac{h(x)}{2} \frac{\partial P}{\partial x}-\frac{\eta U}{h(x)}$.
The friction force can be obtained by integration of Eq. (7):

$F=\int_{-b}^{a} \tau(x) d x$

The power loss is given by Eq. (9) [9]:

$P_{u}=F \times U=U \times \int_{-b}^{a} \tau(x) d x$.

The Reynolds's equation (Eq. (5)) is solved by using the finite difference method and the application of the above approximations with boundary conditions. Relaxation method is used for finalizing the numerical solution using an initial guess for film thickness equation (Eq. (6)). The Newtonian lubricant is used in the numerical scheme for the lubrication solution. The average Reynolds equation is solved to calculate the distribution of hydrodynamic pressures. The gradients of pressure depend on the film thicknesses. Gauss Seidel iterative numerical scheme is used to solve the Reynolds and the oil film thickness equations simultaneously and show maximum and minimum film thicknesses and pressure fields.

\section{Forces acting on the compression ring}

The contact between the ring and cylinder wall is ensured by the spring action inherent in the ring itself, which expands the ring radially [17]. The ring can be inclined or moved axially up and down in the groove. Here, only the axial movement of the segment in the groove is taken into account and it is assumed that the surfaces of the groove are flat. The forces acting on the ring in the axial direction are shown in Fig. 2 and are expressed as follows [18].

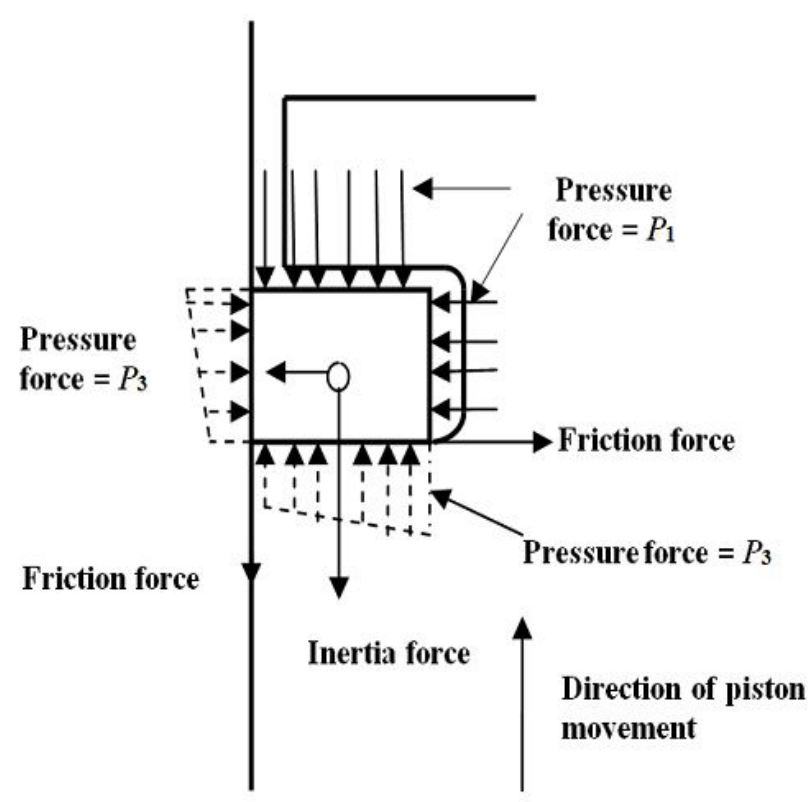

Fig. 2 Forces in axial direction 
The pressure force acting on the ring is given by [19]:

$F_{p}=A_{r} \frac{P_{1}-P_{3}}{2}$,

where $A_{r}$ is the ring area in the radial direction and $P_{i}$ is the pressure force in the regions $i=1 ; 2 ; 3$.

The friction force is calculated from the relation [20]:

$F_{f}=f \times P\left(\pi, d_{r}, T_{r}\right)$,

with

$f=4.8\left(\frac{\mu U}{p T_{r}}\right)$,

where $P$ is the pressure behind the ring, $d_{r}$ the diameter of the ring, $T_{r}$ the thickness of the ring, $U$ the piston speed in $\mathrm{m} / \mathrm{s}$ and $\mu$ the oil viscosity in cst.

The inertia force is due to the mass of the ring and calculated from the relation:

$F_{i}=M_{r} \times a$,

where $M_{r}$ is ring mass $[\mathrm{kg}]$ and $a$ is piston acceleration $\left[\mathrm{m} / \mathrm{s}^{2}\right]$.

\section{Additional modelling considerations}

The numerical simulation in this paper is computed using GT-suite simulation software. The simulation algorithm is established by considering variable piston velocity, gas pressure, and lubrication conditions, as well as variable lubricant viscosity. To solve the Reynolds equation, the boundary conditions $P(x=-b)=P_{1}(t), P(x=a)=P_{2}(t)$ and the piston position during the engine operating cycle must be taken into account (Fig. 3). The vertical velocity of

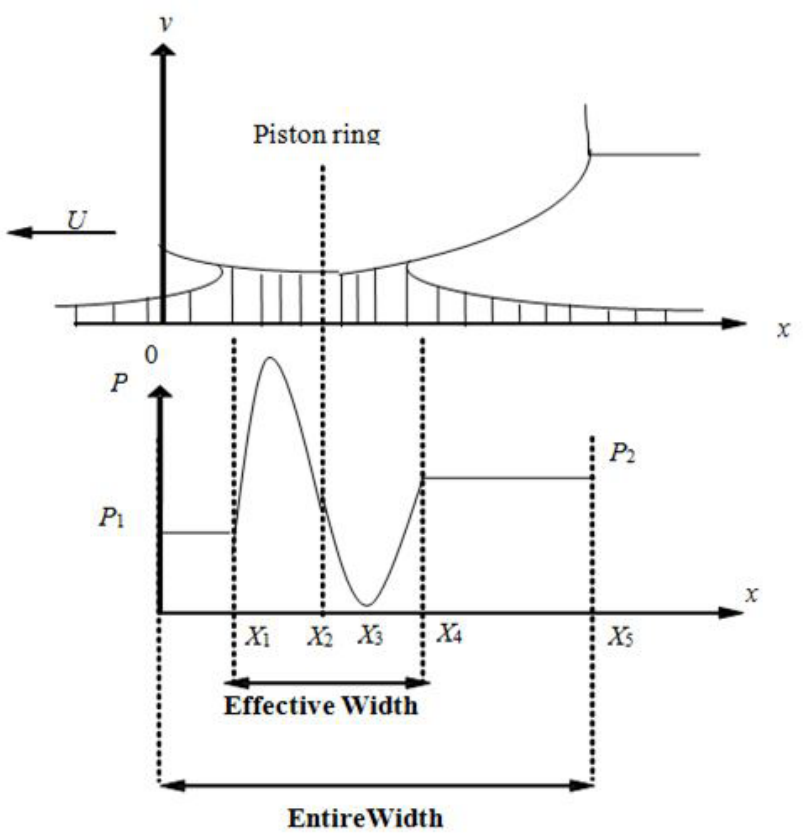

Fig. 3 Open-end boundary conditions. the body $V_{B}=d c / d t$ is determined by the balance between the liner of the ring force $W$ and the lifting force due to the lubricant pressure, expressed by [19]:

$W=\int_{-b}^{a} P(x, t) d x$.

\section{Results and discussion}

Table 1 presents the data used in this investigation. Fig. 4 shows the variation in minimum film thickness versus crank angle for engine speed of $2000 \mathrm{rpm}$ and partial load. In order to validate the film thickness values obtained through simulation, data collected from literature was utilized. Lee et al. [20] conducted experiments on a four-stroke engine and found the film thickness. The same engine parameters were used as input for the simulation software to find the oil film thickness. Since some data were not available, few assumptions were made as inputs of the software, like the ring radial width which was assumed to be 0.3 times the bore, ring material properties where the

Table 1 Engine data.

\begin{tabular}{lcc}
\hline Parameter & Value & Units \\
\hline Connecting Rod Length & 127 & $\mathrm{~mm}$ \\
Crank radius & 31.5 & $\mathrm{~mm}$ \\
Ring Axial Width & 1.63 & $\mathrm{~mm}$ \\
Ring Radial Width & 2.63 & $\mathrm{~mm}$ \\
Bore radius & 48 & $\mathrm{~mm}$ \\
Ring Density & 7900 & $\mathrm{~kg} / \mathrm{m}^{3}$ \\
Ring Elastic Pressure & 93539 & $\mathrm{~N} / \mathrm{m}^{2}$ \\
Ring Modulus of Elasticity & $2.05 \mathrm{e} 11$ & $\mathrm{~Pa}$ \\
Engine speed & 2000 & $\mathrm{rpm}$ \\
Oil Density & 881.5 & $\mathrm{~kg} / \mathrm{m}^{3}$ \\
Oil Viscosity & 0.008736 & $\mathrm{~Pa} \mathrm{~s}$ \\
\hline
\end{tabular}

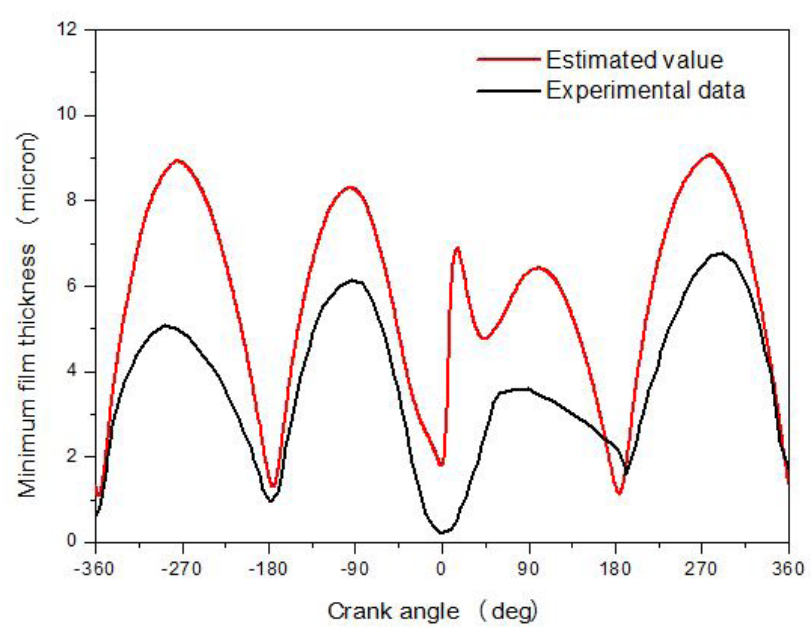

Fig. 4 Minimum film thickness versus crank angle for engine speed of $2000 \mathrm{rpm}$ and partial load. 
ring density was $7900 \mathrm{~kg} / \mathrm{m}^{3}$ and modulus of elasticity was taken to be $205 \mathrm{GPa}$. The output of the simulation code is almost matching with the work done by Lee et al. [20]. The small variations could be due to the assumptions that were made for the input. The film thickness is maximum at the mid-point of the different cycle phases. In the expansion stroke, the oil film thickness is lower. At the dead centers, the film is very thin, especially at the BDC after the expansion stroke and at the TDC at the beginning of the intake stroke, which can lead to high wear of the cylinder wall due to contact between the surfaces.

Fig. 5 shows the variation of hydrodynamic friction force versus crank angle for engine speed of $2000 \mathrm{rpm}$ and partial load. There is a good agreement between the simulated and the experimental data. That maximum friction value is at point of maximum cylinder pressure. The negative part of the curve is due to the change of piston speed direction through the reciprocating motion. It has been observed that the highest friction force value occurred during the expansion stroke with a peak of $185 \mathrm{~N}$, it mainly occurs near the top dead center of combustion, and the value of the friction force is obviously higher than that of the other moments.

Fig. 6 shows the variation of hydrodynamic power losses versus the crank angle at partial load and an engine speed of $2000 \mathrm{rpm}$. The comparison between the estimated value and the experimental data is in good agreement. During the operating cycle of the engine, the maximum power losses for both results variants are all reached at mid-stroke of the piston and then cancel each other out at TDC and TDC, corresponding to the piston velocity variation. The maximum values of the simulated and experimental results are shown in the expansion period.

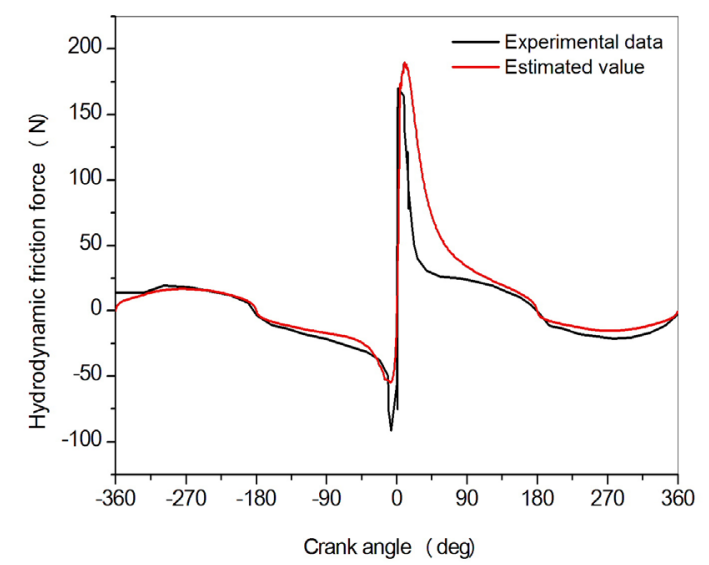

Fig. 5 Hydrodynamic friction force versus crank angle for engine speed of $2000 \mathrm{rpm}$ and partial load.

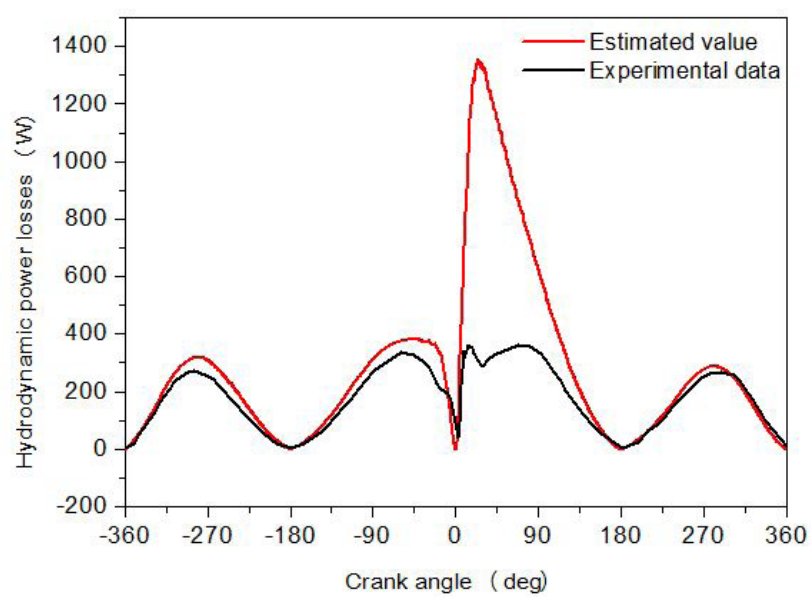

Fig. 6 Hydrodynamic power losses versus crank angle for engine speed of $2000 \mathrm{rpm}$ and partial load.

From Fig. 5, there is a gap of $20.6 \mathrm{~N}$ between the maximum values of the two friction forces (estimated and experimental values). This difference can justify the remoteness between the two power loss curves for the estimated and experimental values in the expansion phase.

\subsection{Effect of engine speed}

Fig. 7 (a), (b) and (c) demonstrates the impact of engine speed on the friction characteristics (friction force, friction power loss and minimum film thickness) between piston rings and cylinder liner with SAE 20W40 engine oil and at full load. From Fig. 7 (a), the friction force reached its peak at TDC during the start of the expansion stroke for the tree engine speed due to increased asperity (boundary) friction force with a decrease in sliding speed at this location. The results showed that friction force increased with increasing engine speed as a result of increasing oil film thickness between piston rings and cylinder liner. This increase was strongly observed at $2000 \mathrm{r} / \mathrm{min}$.

From Fig. 7 (b), the power losses were observed to reach its peak at mid-stroke where the reciprocating speed reached its maximum and hence the oil film thickness and the hydrodynamic shear being at its minimum at TDC and BDC locations where the speed and oil film thickness are critically low. Moreover, the power losses increase with increasing the sliding speed. This behavior might be attributed to the increase in hydrodynamic shear strength resulting from the increase in the oil film thickness.

From Fig. 7 (c), the oil film thickness reached its maximum value in the middle of the stroke where there is hydrodynamic lubrication, while the minimum oil film thicknesses tend to be lower at TDC and BDC. These are 


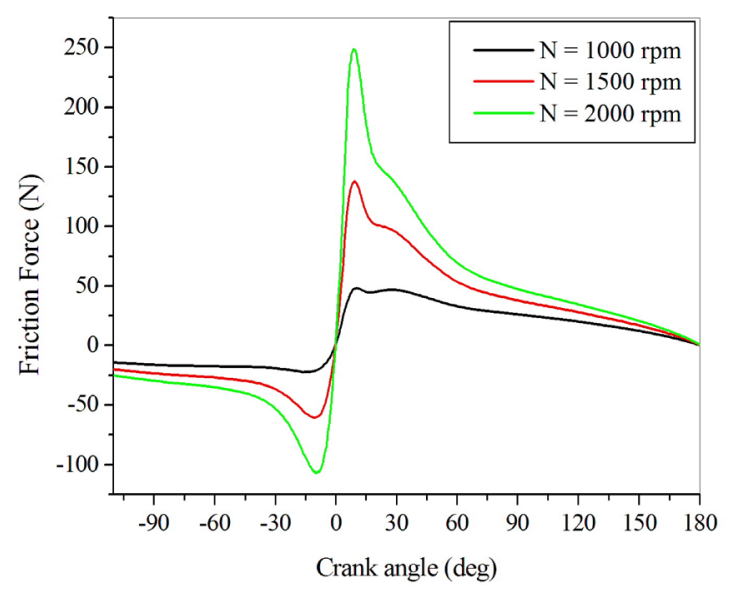

(a)

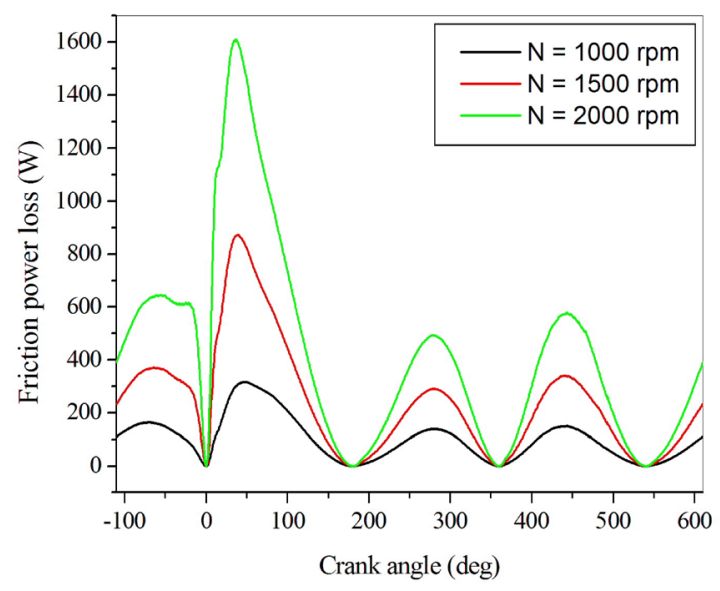

(b)

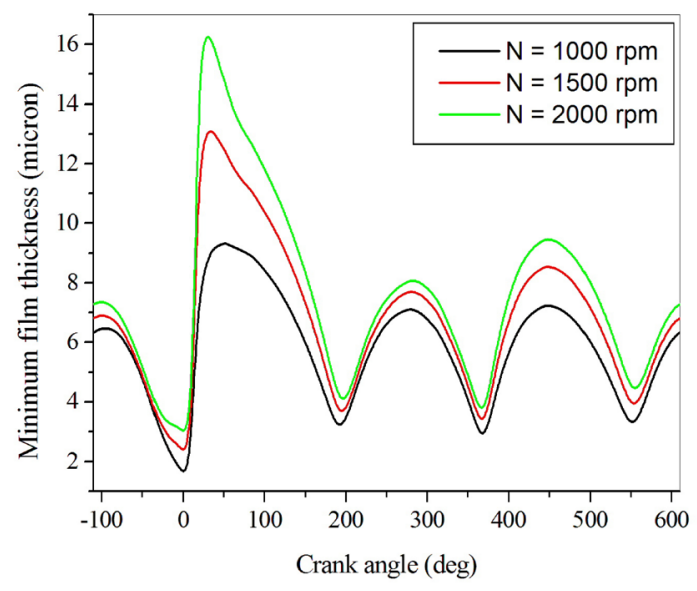

(c)

Fig. 7 (a) Variation of the friction force versus crank angle for different engine speed at full load, (b) variation of the friction power loss versus crank angle for different engine speed at full load, (c) variation of the minimum film thickness versus crank angle for different engine speed at full load. likely to be the points where the piston ring undergoes metallic contact with the cylinder liner (boundary lubrication). In general, the oil film thickness increased with an increase in the engine speed (reciprocating sliding speed).

\subsection{Effect of engine load}

Fig. 8 (a), (b) and (c) shows the simulated results for the friction characteristics of the piston's top compression ring. Fig. 8 (c) shows that the minimum oil film thickness is nearly zero at TDC following the compression stroke due to the increasing of cylinder pressure with the increased of load, which reduced the thickness of the oil film. In addition, the minimum oil film thickness increases with engine load. The friction force by direct asperity contact increased suddenly due to cylinder pressure at TDC. The friction force similarly increased with engine load (Fig. 8 (a)). From Fig. 8 (b), the power loss of the first compression ring had a peak near the middle of the each stroke. This is because the piston sliding velocity has a large influence on the friction power loss calculation. Although the piston sliding velocity is very low, there was a peak power loss near TDC due to a very large friction force in the expansion stroke. Analogously, the first compression ring power loss increases with engine load at the compression stroke.

Fig. 9 presents the friction coefficient variation versus engine loads for engine speed of 1500 and $2000 \mathrm{rpm}$. The friction coefficient was found minimum for low load and maximum for full load. The reason for minimum friction coefficient for low load is due to the minimum mass fuel injected in the combustion period resulting a minimum force acting between the top ring and the cylinder liner. The total force can be reduced by using tribopads inserted into the piston and tribo-inserts inserted into the cylinder liner [16].

\section{Conclusion}

The theoretical results obtained with the numerical model developed by using of the GT-Suite software prove that the engine speed and engine load have an important effect on the tribological behavior of the system piston ring-cylinder liner. The modification of the engine speed and engine load contributes to the reduction of frictional power losses and thus to the improvement of the tribological performance of the internal combustion engine. At mid-stroke of the piston motion, thicker oil films were observed despite the presence of higher hydrodynamic frictional forces and lower oil viscosity. There was a good agreement between 


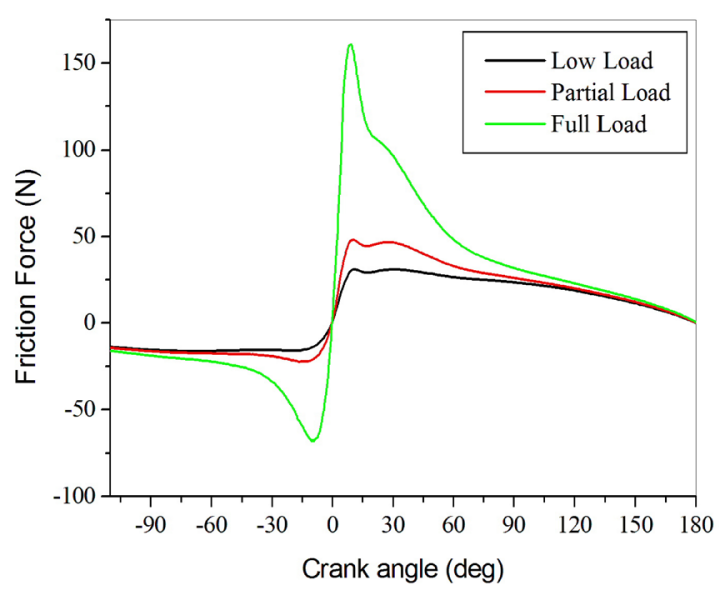

(a)

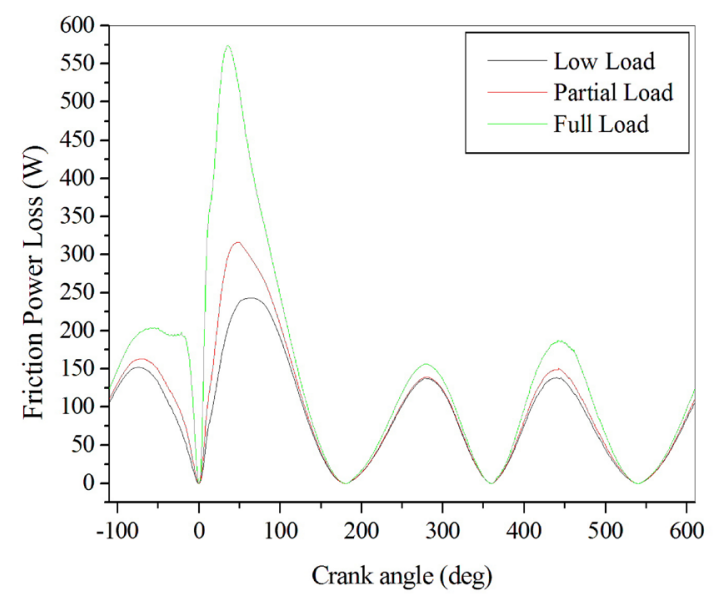

(b)

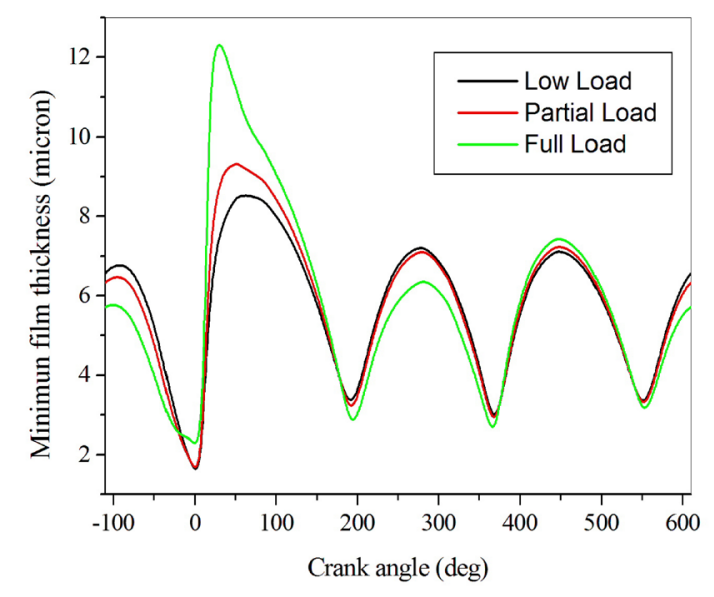

(c)

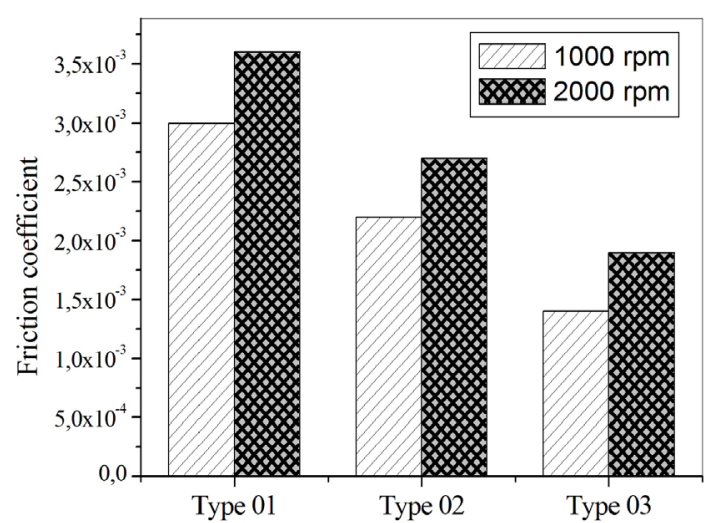

Fig. 9 Friction coefficient versus engine speed and engine load.

the results obtained with the developed numerical model and those of the experimental data. In the present study, the following result could be deduced; the increase in engine speed (from 1000 to $2000 \mathrm{rpm}$ ) and engine load (from low to full load) increases the friction force, friction power loss and minimum film thickness.

Despite a large number of phenomena have been already taken into account, many other ones which could significantly affect tribological performance, have been omitted. In the future these authors plan to take into account occurrence of bore distortion orders to investigate the sealing capacity of the ring-pack in terms of ring dynamics, interring pressures and mass flows.

\section{Acknowledgement}

This study was performed under the framework of "Projet Impact Socio-Economique" Contract No 362 funded by the General Directorate of Algerian Scientific Research (DGRSDT).

Fig. 8 (a) Variation of the friction force versus crank angle for different engine load at engine speed of $2000 \mathrm{rpm}$, (b) variation of the friction power loss versus crank angle for different engine load at engine speed of $2000 \mathrm{rpm}$, (c) variation of the minimum film thickness versus crank angle for different engine load and engine speed of $2000 \mathrm{rpm}$. 


\section{References}

[1] Harigaya, Y., Suzuki, M. Takiguchi, M. "Analysis of Oil Film Thickness on a Piston Ring of Diesel Engine: Effect of Oil Film Temperature", Journal of Engineering for Gas Turbines Power, 125(2), pp. 596-603, 2003.

https://doi.org/10.1115/1.1501078

[2] Radakovic, D. J., Khonsari, M. M. "Heat Transfer in a Thin-Film Flow in the Presence of Squeeze and Shear Thinning: Application to Piston Rings", Journal of Heat Transfer, 119(2), pp. 249-257, 1997. https://doi.org/10.1115/1.2824217

[3] Chaudhari, T., Sutaria, B. "Investigation of friction characteristics in segmented piston ring liner assembly of IC engine", Perspectives in Science; recent trends in engineering and materials sciences, 8, pp. 599-602, 2016.

https://doi.org/10.1016/j.pisc.2016.06.032

[4] Guo, Y. B., Lu, X. Q., Zou, D. Q., He, T., Li, W. Y., Li, Z. J. "Analysis of Piston Ring Lubrication with Different Lubricant Supply", Advanced Materials Research, 199-200, pp. 700-706, 2011. https://doi.org/10.4028/www.scientific.net/AMR.199-200.700

[5] Mishra, P. C., Rahnejat, H., King, P. D. "Tribology of the ring-bore conjunction subject to a mixed regime of lubrication", Proceedings of the Institution of Mechanical Engineers, Part C: Journal of Mechanical Engineering Science, 223(4), pp. 987-998, 2008. https://doi.org/10.1243/09544062JMES1220

[6] Soualmia, A., Bouchetara, M. "Numerical modeling of the hydrodynamic behaviour of the couple piston liner", Mechanika, 21(6), pp. $450-456,2015$.

https://doi.org/10.5755/j01.mech.21.6.7035

[7] Arcoumanis, C., Duszynski, M., Flora, H., Ostovar, P. "Development of a Piston-Ring Lubrication Test-Rig and Investigation of Boundary Conditions for Modelling Lubricant Film Properties", SAE Transactions: Journal of Fuels \& Lubricants, 104(4), pp. 1433-1451, 1995.

https://doi.org/10.2307/44615179

[8] Wakuri, Y., Soejima, M., Ejima, Y., Hamatake, T., Kitahara, T. "Studies on Friction Characteristics of Reciprocating Engine", In: Fuels \& Lubricants, Meeting \& Exposition, Toronto, ON, Canada, 1995, Article Number: 952471.

https://doi.org/10.4271/952471

[9] Jeng, Y. R. "Theoretical Analysis of Piston-Ring Lubrification Part I-Fully Flooded Lubrication", Tribology Transactions, 35(4), pp. 696-706, 1992.

https://doi.org/10.1080/10402009208982174

[10] Wannatong, K., Chanchaona, S., Sanitjai, S. "Simulation algorithm for piston ring dynamics", Simulation Modelling Practice and Theory, 16(1), pp. 127-146, 2008.

https://doi.org/10.1016/j.simpat.2007.11.004

[11] Usman, A., Park, C. W. "Optimizing the tribological performance of textured piston ring-liner contact for reduced frictional losses in SI engine: Warm operating conditions", Tribology International, 99, pp. 224-236, 2016.

https://doi.org/10.1016/j.triboint.2016.03.030
[12] Delprete, C., Razavykia, A. "Piston ring-liner lubrication and tribological performance evaluation: A review", Proceedings of the Institution of Mechanical Engineers, Part J: Journal of Engineering Tribology, 232(2), pp. 193-209, 2018.

https://doi.org/10.1177/1350650117706269

[13] Delprete, C., Razavykia, A., Baldissera, P. "Detailed analysis of piston secondary motion and tribological performance", International Journal of Engine Research, pp. 1-15, 2019. https://doi.org/10.1177/1468087419833883

[14] Notay, R. S., Priest, M., Fox, M. F. "The influence of lubricant degradation on measured piston ring film thickness in a fired gasoline reciprocating engine", Tribology International, 129, pp. 112-123, 2019. https://doi.org/10.1016/j.triboint.2018.07.002

[15] Balakrishnan, S., Rahnejat, H. "Isothermal transient analysis of piston skirt-to-cylinder wall contacts under combined axial, lateral and tilting motion", Journal of Physics D: Applied Physics, 38(5), pp. 787-799, 2005. https://doi.org/10.1088/0022-3727/38/5/018

[16] Morris, N., Rahmani, R., Rahnejat, H., King, P. D., Fitzsimons, B. "The influence of piston ring geometry and topography on friction", Proceedings of the Institution of Mechanical Engineers, Part J: Journal of Engineering Tribology, 227(2), pp. 141-153, 2013. https://doi.org/10.1177/1350650112463534

[17] Zavos, A. B., Nikolakopoulos, P. G. "Simulation of piston ring tribology with surface texturing for internal combustion engines", Lubrication Science, 27(3), pp. 151-176, 2015.

https://doi.org/10.1002/1s.1261

[18] Mohamad, S. A., Lu, X., Zheng, Q. "Numerical modeling of lubrication of piston ring of two-stroke marine diesel engine considering the effect of multi-scale grooves on the cylinder liner", Proceedings of the Institution of Mechanical Engineers, Part J: Journal of Engineering Tribology, 229(8), pp. 989-1002, 2015. https://doi.org/10.1177/1350650114556400

[19] Bertocchi, L., Dini, D., Giacopini, M., Fowell, M. T., Baldini, A. "Fluid film lubrication in the presence of cavitation: a mass-conserving two-dimensional formulation for compressible, piezoviscous and non-Newtonian fluids", Tribology International, 67, pp. 61-71, 2013. https://doi.org/10.1016/j.triboint.2013.05.018

[20] Lee, S., Kang, J., Park, S. "Measurement and modeling of crank train friction in light -duty diesel engines", Journal of Mechanical Science and Technology, 34(2), pp. 889-903, 2020. https://doi.org/10.1007/s12206-020-0139-y 